Correction

\title{
Correction: Selenoprotein K deficiency inhibits melanoma by reducing calcium flux required for tumor growth and metastasis
}

\author{
Michael P. Marciel ${ }^{1}$, Vedbar S. Khadka², Youping Deng ${ }^{2}$, Pascal Kilicaslan ${ }^{3}$, Andrew \\ Pham $^{1}$, Pietro Bertino ${ }^{1}$, Katie Lee ${ }^{1}$, Suzie Chen ${ }^{4}$, Natalija Glibetic ${ }^{5}$, FuKun W. \\ Hoffmann ${ }^{1}$, Michelle L. Matter ${ }^{5}$ and Peter R. Hoffmann ${ }^{1}$ \\ ${ }^{1}$ Department of Cell and Molecular Biology, John A. Burns School of Medicine, University of Hawaii, Honolulu, Hawaii, U.S.A. \\ 2 Bioinformatics Core in the Department of Complementary and Integrative Medicine, John A. Burns School of Medicine, \\ University of Hawaii, Honolulu, Hawaii, U.S.A. \\ ${ }^{3}$ Biotechnology Department, University of Applied Sciences Mannheim, Mannheim, Germany \\ ${ }^{4}$ Ernest Mario School of Pharmacy, Rutgers University, Piscataway, New Jersey, U.S.A. \\ ${ }^{5}$ The University of Hawaii Cancer Center, Honolulu, Hawaii, U.S.A.
}

Published: July 20, 2018

Copyright: Marciel et al. This is an open-access article distributed under the terms of the Creative Commons Attribution License 3.0 (CC BY 3.0), which permits unrestricted use, distribution, and reproduction in any medium, provided the original author and source are credited.

This article has been corrected: The corrected author name is given below:

\section{Youping Deng}

Original article: Oncotarget. 2018; 9:13407-13422. https://doi.org/10.18632/oncotarget.24388 